\title{
ENTRE EVENTOS E EPISÓDIOS: RITMO CLIMÁTICO E EXCEPCIONALIDADES PARA UMA ABORDAGEM GEOGRÁFICA DO CLIMA NO MUNICÍPIO DO RIO DE JANEIRO ${ }^{1}$
}

\author{
ARMOND, Núbia Beray - nubiaarmond@hotmail.com \\ Doutoranda em Geografia - Professora Assistente do Departamento de \\ Geografia Física da Universidade do Estado do Rio de Janeiro \\ SANT'ANNA NETO, João Lima - joaolima@fct.unesp.br \\ Professor Titular - Professor do Programa de Pós-Graduação em Geografia da \\ FCT/UNESP - Presidente Prudente
}

\begin{abstract}
RESUMO: As metrópoles brasileiras caracterizam-se pela conflituosa relação entre os grupos sociais e as dinâmicas da natureza. No caso das chuvas, essas influências se dão através dos diferentes totais de precipitação que, não necessariamente elevados, podem deflagrar variados transtornos. Nesse contexto, o artigo tem como objetivo identificar os sistemas atmosféricos deflagradores de excepcionalidades climáticas e as suas diferentes ocorrências no espaço urbano. As excepcionalidades foram definidas em dois eixos: o primeiro, referente aos totais pluviométricos superiores a $20 \mathrm{~mm}$ em $24 \mathrm{~h}$, denominados eventos extremos. O segundo, dos eventos que deflagraram impactos relacionados ao espaço urbano - chamados episódios extremos. Foram utilizados dados de 32 postos pluviométricos da Rede AlertaRio (1999-2012), dispostos a cada 15 minutos e agrupados em totais mensais e anuais, através do software Microsoft Excel 2013. Foram extraídos cinco anos-padrão e, no interior deles, analisados os dias nos quais ocorreu o limiar de $20 \mathrm{~mm} / 24 \mathrm{~h}$ (excepcionalidade). A localização dos episódios se deu pela identificação dos bairros noticiados no Jornal O Extra. Aproximadamente $65 \%$ das excepcionalidades foram desencadeadas pela Frente Polar Atlântica. Caso considere-se os sistemas associados e/ou gerados pela FPA, o percentual chega a $85 \%$. Nem todo evento extremo deflagrou episódios extremos. A intensidade das chuvas não foi determinante para a ocorrência de repercussões, mas sim a natureza dos lugares.
\end{abstract}

Palavras- chaves: Eventos extremos; Episódios extremos; Excepcionalidades; Geografia do Clima; Rio de Janeiro.

BETWEEN EVENTS AND EPISODES: CLIMATIC RHYTHM AND EXCEPTIONALITIES TO A GEOGRAPHY OF CLIMATE APPROACH IN RIO DE JANEIRO CITY

ABSTRACT: Brazilian metropolises are characterized by a conflictive relationship between social groups and natural dynamics. In rainfall case, these influences take place through different precipitation levels which not necessarily high can trigger disturbances. This article's main goal is to identify the atmospheric systems that trigger climatic exceptionalities and analyze their different occurrences in urban space. The exceptionalities were defined about two axes: first related to rainfall levels above $20 \mathrm{~mm}$ in $24 \mathrm{~h}$, defined as extreme events. Second events which triggered impacts related to urban space - defined as extreme episodes. Rainfall data from 32 AlertaRio's rain gauges (1999-2012) were used, organized in 15-minutes data grouped in monthly and annual totals. 5 standard years were extracted and its extreme days analyzed. The extreme episodes' localization was given by neighborhood reported in O Extra. About $65 \%$ of the exceptionalities were triggered by Atlantic Polar Front. Considering associated systems or those generated by Atlantic Polar Front, the values can reach $85 \%$. Not every extreme

\footnotetext{
${ }^{1}$ Este artigo é resultado da dissertação de mestrado, defendida no ano de 2014, intitulada "Entre eventos e episódios: as excepcionalidades das chuvas e os alagamentos no espaço urbano do Rio de Janeiro", sob a orientação do co-autor deste trabalho no Programa de Pós-Graduação em Geografia da FCT/UNESP - Presidente Prudente.
} 
event triggered extreme episodes. The intensity of rainfall was not decisive for the occurrence of repercussions, but rather, the different nature of places.

Keywords: Extreme events; Extreme episodes; Exceptionalities; Geography of Climate; Rio de Janeiro

\section{ENTRE LOS EVENTOS Y LOS EPISODIOS: RITMO CLIMATICO Y EXCEPCIONALIDADES A UM ENFOQUE GEOGRÁFICO DEL CLIMA EN EL MUNICÍPIO DE RÍO DE JANEIRO}

RESUMEN: Las metrópolis brasileñas se caracterizan por conflictos de relación entre los grupos sociales y la dinámica de la naturaliza. En caso de lluvia, estas influencias se dan a través de los diferentes totales de precipitación que, no necesariamente alta, puede provocar trastornos variados. En este contexto, el artículo tiene como objetivo identificar los sistemas atmosféricos deflagradores de excepcionalidades climáticas y sus diferentes ocurrencias en el espacio urbano. Las excepcionalidades fueron definidas en dos ejes: en el primer, se refiere a los totales pluviométricos superiores a $20 \mathrm{~mm}$ en $24 \mathrm{~h}$, denominados eventos extremos. En el segundo, de los eventos que deflagraran impactos relacionados al espacio urbano - llamados episodios extremos. Fueron utilizados datos de 32 estaciones pluviométricas de la red AlertaRio (1999-2012), disponibles a cada 15 minutos e agrupados en totales mensuales y anuales a través del software Excel. Fueron extraídos cinco años-estándar y, en cada uno, analizados los días en los cuales hubo el umbral de $20 \mathrm{~mm} / 24 \mathrm{~h}$ (excepcionalidad). La ubicación de los episodios extremos se dio por la identificación de los barrios reportados en el periódico O Extra. Acerca de $65 \%$ de las excepcionalidades fueron desencadenadas por la Frente Polar Atlántica. En caso de considerar los sistemas asociados y/o generados por la FPA, el porcentaje puede llegar a $85 \%$. No todos los eventos extremos provocaron episodios extremos. La intensidad de las lluvias no fue decisiva para la ocurrencia de efectos, pero si la naturaleza de los lugares.

Keywords: Eventos extremos; Episodios extremos; Excepcionalidades; Geografía del Clima; Rio de Janeiro

\section{ENTRE ÉVÉNEMENTS ET ÉPISODES: RYTHME CLIMATIQUE ET EXCEPTIONNELS À UNE GÉOGRAPHIE D'APPROCHE CLIMATIQUE À RIO DE JANEIRO}

RESUMÉ: Les métropoles brésiliennes se caractérisent par une relation conflictuelle entre les groupes sociaux et la dynamique naturelle. Dans le cas des précipitations, ces influences se produisent à travers des niveaux de précipitation différents, qui ne sont pas nécessairement élevés, peuvent déclencher des perturbations. Le but de cet article est d'identifier les systèmes atmosphériques qui déclenchent des phénomènes climatiques exceptionnels et d'analyser leurs différentes occurrences dans l'espace urbain. Les exceptionnalités ont été définies autour de deux axes: d'abord, les niveaux de précipitations supérieurs à $20 \mathrm{~mm}$ en $24 \mathrm{~h}$, définis comme des événements extrêmes. Deuxièmement, les événements qui ont déclenché des impacts liés à l'espace urbain définis comme des épisodes extrêmes. Les données pluviométriques de 32 pluviomètres d'AlertaRio (1999-2012) ont été utilisées, organisées en données de 15 minutes regroupées en totaux mensuels et annuels. 5 années standard ont été extraites et ses jours extrêmes ont été analysés. La localisation des épisodes extrêmes a été donnée par voisinage rapporté dans 0 Extra. Environ $65 \%$ des exceptions ont été déclenchées par Atlantic Polar Front. En considérant les systèmes associés ou ceux générés par Atlantic Polar Front, les valeurs peuvent atteindre $85 \%$. Pas tous les événements extrêmes ont déclenché des épisodes extrêmes. L'intensité des précipitations n'a pas été décisive pour l'apparition des répercussions, mais plutôt la nature différente des lieux.

Mots Clés: Événements extrêmes; Épisodes extrêmes; Exceptionalités; Géographie du climat; Rio de Janeiro. 


\section{INTRODUÇÃO E PROCEDIMENTOS}

As contradições na apropriação do sítio urbano é processo inerente à produção do espaço, sobretudo nos países de capitalismo tardio. Tal processo historicamente produzido reflete no "espaço físico" de qualquer área urbana, e ainda mais nos espaços metropolitanos. Esta é a realidade do município do Rio de Janeiro, situado na faixa tropical atlântica (DE MARTONNE, 1944), no litoral sudeste do Brasil: uma grande cidade entre a montanha e a floresta (ABREU, 1992).

A interação dos fatores geográficos (maritimidade e orografia) com os elementos climáticos (sobretudo a precipitação), atrelados a uma complexa, contraditória e, por natureza, desigual e dinâmica de produção do espaço no Rio de Janeiro faz com que uma proposta de análise geográfica do Clima seja não apenas uma opção teórica, mas uma obrigação ontológica.

Obrigação ontológica porque uma abordagem geográfica do clima demanda entender que o espaço geográfico é socialmente produzido, e não deve ser encarado como receptáculo, inerte e dissociado das dinâmicas do tempo, do clima e dos impactos deflagrados. Pelo contrário, as contradições econômicas, sociais, culturais e ambientais, desiguais e inerentes a cada recorte espacial, devem ser assumidas numa perspectiva histórica, como resultado transitório de um campo complexo de tensões entre as classes sociais e seus grupos, agentes e instituições. Como tal, fenômenos climáticos como ondas de calor e de frio, poluição atmosférica e excepcionalidades de precipitação, apesar de serem considerados "democráticos" do ponto de vista da sua ocorrência por não pressupor uma seletividade espacial, se tornam altamente perversos do ponto de vista de seus efeitos. Assim, longe de se constituírem como "agentes naturais", os fenômenos climáticos são, em seus efeitos, indicadores das diferentes formas a partir das quais o espaço é produzido. As chuvas (como poderiam ser as ondas de calor/frio, as ilhas de calor, consequências da poluição atmosférica, entre outros) deflagram (NUNES, 2009), descortinam e evidenciam a faceta ambiental de um processo de produção do espaço que é, por natureza, desigual.

Por conta disso, foi realizado exercício teórico e conceitual de delinear possibilidades de abordagem das excepcionalidades das chuvas a partir de uma Geografia do Clima. Neste caso, elaborou-se a separação entre o que chamamos de eventos extremos e episódios extremos (ARMOND, 2014).

Os eventos extremos consistem em elevados totais de precipitação, em geral acima dos limiares definidos como médios. Neste artigo, os eventos foram concebidos como dias nos quais a chuva acumulada ultrapassou o total de $20 \mathrm{~mm}$, mas sem a ocorrência de impactos associados. A escolha desse limiar se deu em associação com a definição do que se denominou episódios extremos neste artigo.

Os episódios extremos foram abordados como os dias nos quais os totais de precipitação ocorreram acima de $20 \mathrm{~mm} / 24 \mathrm{~h}$, mas que tiveram impactos sobretudo de natureza hidrológica - em diferentes localidades do município. Assim, o artigo apresenta as caracterizas climáticas e atmosféricas do município 
do Rio de Janeiro, com a abordagem da climatologia dinâmica. Enfoca-se na configuração dos elementos de clima em interação os fatores climáticos, destacando principalmente os sistemas produtores de chuva, a orografia e a situação geográfica de costa.

A primeira parte deste artigo trata da construção da Climatologia Geográfica e, posteriormente, da sua passagem em direção à Geografia do Clima, referenciais que partem da análise do clima como fenômeno geográfico até as contradições na produção do espaço.

Em seguida, realizou-se uma revisão sobre as excepcionalidades a partir de trabalhos desenvolvidos fora e dentro da Geografia. O objetivo foi determinar o que tem sido tomado enquanto evento extremo na literatura científica em geral e o que a ciência geográfica tem considerado enquanto eventos extremos para, então, realizar a proposição de abordagem das excepcionalidades em duas perspectivas: a dos eventos extremos e a dos episódios extremos. É nesse contexto que os limiares de $20 \mathrm{~mm}$ em $24 \mathrm{~h}$ foram definidos, posto que a literatura apresenta a ocorrência de impactos com chuvas mesmo abaixo desse limiar.

Na terceira parte, são apresentados os resultados produzidos a partir da utilização de técnicas e referenciais analíticos advindos da tradição da Climatologia Geográfica e Geografia do Clima. Foram utilizados os dados de 32 telepluviômetros da Fundação AlertaRio (Ffigura 1), que subsidiaram a análise temporal e espacial das excepcionalidades.

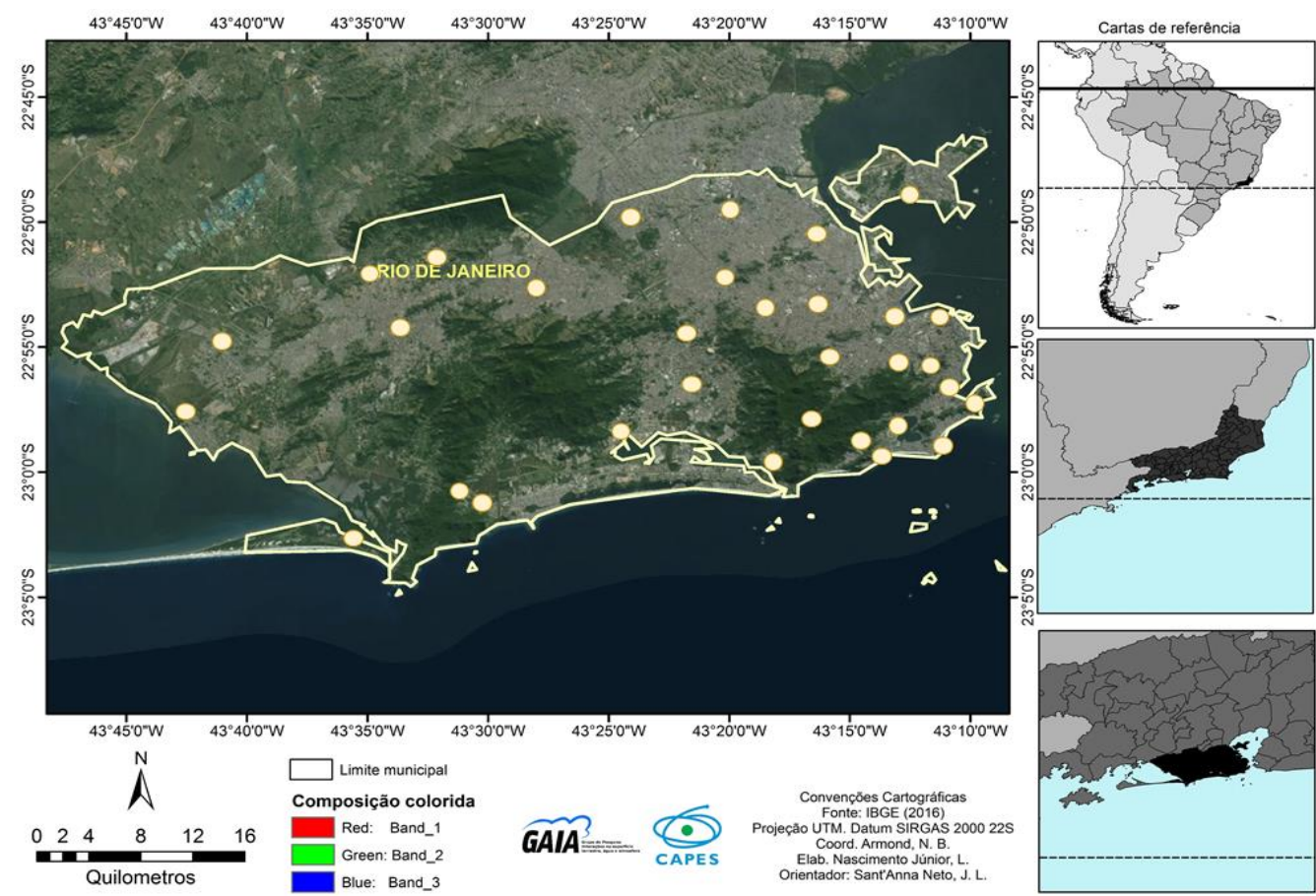

Figura 1 - Localização da área de estudo, com os postos pluviométricos utilizados. Fonte: Autores. 
Os dados de precipitação foram adquiridos dispostos a cada 15 minutos. Em ambiente de planilha eletrônica Microsoft Excel 2016, os dados foram agrupados em totais diários, mensais, sazonais e anuais. As falhas de dados foram preenchidas conforme técnica de rebatimento, com a média da triangulação de valores de mais duas estações mais próximas e com altitude semelhante (ARMOND, 2014).

Para proceder à identificação e análise das excepcionalidades, optou-se pelos procedimentos metodológicos legados por Monteiro (1971), aplicados em Armond (2014, 2016): a escolha de anos-padrão e a realização de análise rítmica.

Foram escolhidos cinco anos-padrão, conforme em Sant'Anna Neto (1995): 1999 (ano seco), 2006 (ano habitual) e 2010, 2011 e 2012 (anos chuvosos).

A análise rítmica das excepcionalidades foi realizada utilizando-se dos dados climatológicos da estação meteorológica do Aeroporto do Galeão, operada pelo INMET, e estudo dos campos de pressão e dos principais sistemas atmosféricos atuantes em escala global, pautados pelos princípios de física da atmosfera e interação entre os elementos climáticos presentes em Monteiro (1971), Nimer (1979) e Mendonça e Danni-Oliveira (2007).

A identificação de eventos e episódios extremos se deu de acordo com notícias do Jornal O Extra, localizadas a partir da pesquisa dos verbetes "enchente", "alagamento", "inundação" e "desastre" no banco de dados diário do jornal. Foram escolhidos aquelas notícias situadas no interior dos limiares de precipitação. Aliás, o limiar de $20 \mathrm{~mm}$ em $24 \mathrm{~h}$ foi o mínimo escolhido. Outras excepcionalidades puderam ser identificadas e foram categorizadas em outras faixas de precipitação, como de $20 \mathrm{~mm}$ a $40 \mathrm{~mm}$ em $24 \mathrm{~h}$; de $40 \mathrm{~mm}$ a $60 \mathrm{~mm}$ em $24 \mathrm{~h}$; de $60 \mathrm{~mm}$ a $80 \mathrm{~mm}$ em $24 \mathrm{~h} ; 80 \mathrm{~mm}$ a $100 \mathrm{~mm}$ em $24 \mathrm{~h}$; acima de $100 \mathrm{~mm}$ em $24 \mathrm{~h}$.

A análise rítmica aplicada a estas excepcionalidades foi realizada com o uso de dados meteorológicos de superfície (Estação Galeão), cartas sinóticas adquiridas no site da Marinha do Brasil, e imagens do satélite GOES, disponível no site do CPTEC.

A identificação dos sistemas atmosféricos atuantes e deflagradores de excepcionalidades se deu a partir da relação entre estes dados e instrumentos. A quantidade de sistemas atmosféricos foi contabilizada e analisada em termos absolutos e percentuais. Finalmente, relacionou-se às áreas mais afetadas segundo as notícias.

No que se refere às considerações finais, discorreu-se sobre a relação entre os eventos e os episódios, a intensidade das chuvas em cada um deles, e a constatação de que a precipitação, mesmo as de elevados totais, não são determinantes para as ocorrências de impactos. Este debate é contemplado na última parte. 


\section{DINÂMICA CLIMÁTICA E PRODUÇÃO DO ESPAÇO GEOGRÁFICO DO RIO DE JANEIRO}

Assim como a maior parte das mais antigas cidades brasileiras, sua situação costeira e suas condições geológicas, geomorfológicas, pedológicas, climáticas e biogeográficas consistiram em importantes elementos para a produção singular da cidade do Rio de Janeiro.

De acordo com Galvão (1992), no século XVI ocorreu o período de conhecimento da natureza pelo homem na cidade. Reconhecidos como obstáculos ou facilitadores, elementos como a Baía de Guanabara, a baixada fluminense e os maciços costeiros figuraram uma relação que a autora definiu como conflituosa no processo de ocupação do Rio de Janeiro (figura 1).

Abreu (2006), falando sobre séculos adiante (com ênfase na passagem do século XVIII para o XIX), demonstrou que o processo de urbanização do Rio de Janeiro foi caracterizado pela incorporação de áreas "periféricas" para a ocupação, com o afastamento das classes média/alta do Centro inicialmente em direção à Zona Sul (Flamengo, Botafogo, Copacabana, Leme, Ipanema) e, mais recentemente, em direção aos bairros do Leblon, Barra da Tijuca e mesmo Recreio dos Bandeirantes. Enquanto isso, aos trabalhadores restaram os arrabaldes e, após o século XIX, com a passagem para o período industrial e a constituição e consolidação das linhas de bonde e trem, a transformação dos arrabaldes naquilo que viria a se constituir, material, simbólica, teórico e conceitualmente, no subúrbio carioca (FERNANDES, 2011).

Pelo menos desde o século XVII, ocorreu o desmanche de morros e aterramento de áreas de manguezal e alagadiços para ampliação da parte continental da cidade, fenômeno ocorrido sobretudo na porção leste do município, fronteiriça com a Baía de Guanabara. Estudos anteriores (ABREU, 2006; COELHO, 2007; ANDREATTA et al, 2009) indicaram estas alterações não apenas como um processo ocorrido no passado, mas sim como uma marca, uma característica fundante e viva, presente no processo de urbanização no Rio de Janeiro. Nos dias atuais, estas alterações continuaram, centradas nestes mesmos bairros, principalmente com as obras relacionadas aos Jogos PanAmericanos (2007), Copa do Mundo de Futebol da Fifa (2014) e Jogos Olímpicos (2016). As constantes alterações no espaço físico do Rio de Janeiro, em geral realizadas para atender interesses dos mais variados (exceto a promoção da qualidade de vida da classe trabalhadora), são elementos importantes para o entendimento de alguns dos principais problemas ambientais urbanos do município (COELHO, 2007).

Atrelada a tamanha complexidade de produção do espaço, o município do Rio de Janeiro situa-se na região sudeste do Brasil, área transicional entre sistemas atmosféricos. Constitui-se em uma zona de confronto entre os sistemas polares e os sistemas tropicais (SERRA e RATISBONNA, 1941; NIMER, 1979; SANT'ANNA NETO, 2005; DERECZYNSKY et al., 2009; ARMOND, 2016). Essa característica faz com que sua condição latitudinal e longitudinal de tropicalidade litorânea seja ainda mais complexificada pela dinâmica climática local.

No que se refere aos fatores geográficos do clima, duas condições são fundamentais para a modulação da dinâmica: a localização do município junto à linha de costa e a orografia (ARMOND, 2016). A situação costeira da cidade faz 
com que a umidade e as temperaturas não sofram alterações demasiado bruscas, mantendo os desvios padrões próximos às médias. Sua localização em uma área de interface oceano-continente faz com que a água existente na atmosfera seja continuamente alimentada pela umidade que vem do mar. Por isso, consiste em um local de elevada umidade durante todo o ano, com uma variação pouco significativa da temperatura (figura 2).

$\mathrm{Na}$ mesma situação, as rupturas de declividade acontecem de forma brusca em curta distância. Em menos de $25 \mathrm{~km}$, da linha de costa em direção aos setores continentais do município, tem-se altitudes que variam de 0 a 1000 metros. Estas duas condições - bastante características do Brasil tropical atlântico -, influenciam na diversificação da influência dos elementos climáticos em diferentes áreas do município.

Para De Martonne (1944), a parte atlântica em que se situa o Rio de Janeiro pode ser classificada como sob atuação do clima das Serras Litorâneas, caracterizados pelas condições de calor e umidade elevadas, com altos totais de precipitação a barlavento (ARMOND, 2016). Esta tipologia também foi destacada por Conti (1975), em trabalho sobre o eixo lesnordeste paulista.

Sobre os elementos climáticos, Serra e Ratisbonna (1941) identificaram o clima do Rio de Janeiro como altamente influenciado pela relação entre a Alta Subtropical do Atlântico Sul (ASAS), com ventos de sentido NE-SW, e os anticiclones frios polares, de orientação SW-NE.

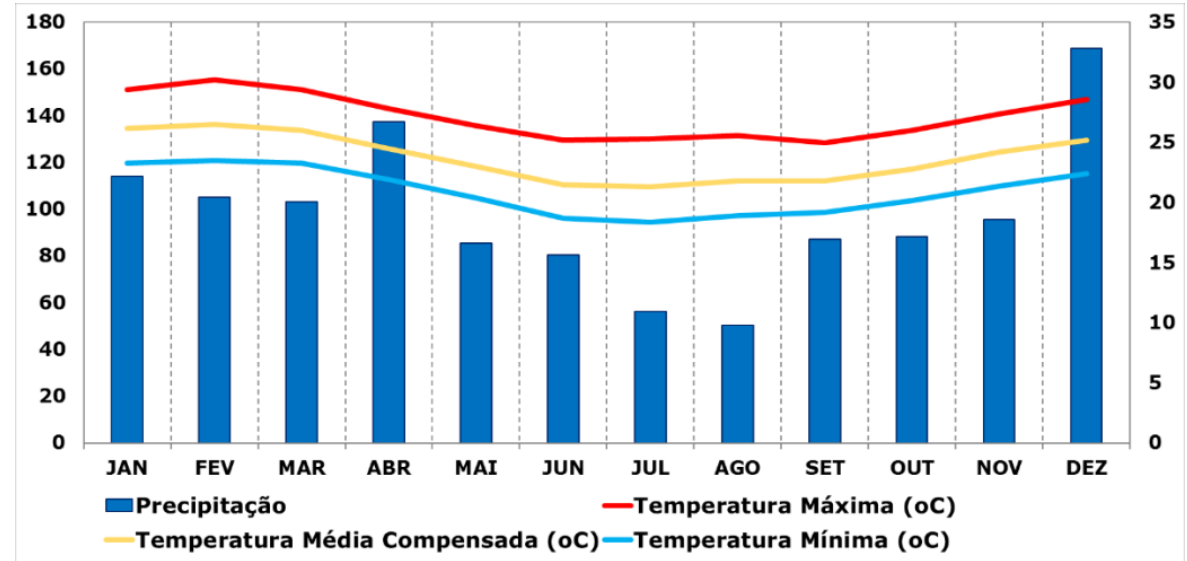

Figura 2 - Climograma com as normais de precipitação, temperatura máxima, média compensada e mínima para a estação Galeão (GIG), no município do Rio de Janeiro - RJ Fonte: BDMEP/INMET Elaboração: autores.

Para Nimer (1979), a Massa Polar Atlântica (mPa) é responsável pelo avanço das frentes que ocorrem na região, sobretudo no período de primavera e verão. A frente, formada pelo encontro da $\mathrm{mPa}$ e do ASAS, tem sua área de frontogênese gradativamente mobilizada em direção a latitudes mais baixas no inverno. Esse movimento se dá de acordo com a consistência do ar polar vindo de sul (SANT'ANNA NETO, 2005).

Em período de outono/inverno, a mPa encontra-se bem caracterizada, consistente e fortalecida, podendo avançar com maior contundência e formar 
frentes que chegam em estados do Nordeste brasileiro. Como consequência, na retaguarda da frente atua a $\mathrm{mPa}$, trazendo frio e menor umidade em sua retaguarda. A atuação da $\mathrm{mPa}$ provoca elevada estabilidade do tempo atmosférico, com céu claro, temperaturas mais amenas, totais de precipitação reduzidos e menos umidade relativa do ar. No caso do Rio de Janeiro, a umidade e a precipitação são reduzidas, mas sua condição litorânea e suas características orográficas fazem com que, habitualmente, não se atinja valores inferiores a $50 \%$ de umidade e que chova em todos os meses do ano.

Já em período de primavera/verão, a mPa encontra-se mais enfraquecida e o ASAS mais fortalecido. Assim, seu avanço rumo às latitudes baixas ocorre com menos força, o que forma áreas frontogenéticas sobre o Sul e o Sudeste brasileiro, dando início à estação chuvosa sobre esta área. No Sudeste, este período vai de outubro a março e é caracterizado pelas chuvas, elevada umidade do ar e temperaturas altas, posto que a $\mathrm{mPa}$ enfraquecida já se tropicaliza (ou, se continentaliza) em sua trajetória sobre a porção continental sul da América do Sul. Monteiro (1969, 1971) identificava esta caracterização da mPa alterando sua denominação, chamando-a de "massa polar velha".

Nos meses em que a $\mathrm{mPa}$ se apresenta fortemente constituída e caracterizada, a diferença barométrica entre ela e o ASAS faz com que uma inclinada e elevada rampa de nuvens se constitua, formando temporais de rápida duração e de média magnitude, mas que podem deflagrar transtornos. Estas condições podem ser encontradas nos meses de inverno e naqueles de transição, principalmente outubro/novembro e março/abril.

Já nos meses em que a mPa está enfraquecida, o seu avanço sobre o continente em direção as baixas latitudes não necessariamente pode ocorrer através de uma única mPa constituída. Ao atingir as porções continentais e encontrar-se com os ares do ASAS, a mPa pode se multiplicar em células de baixa pressão, constituindo frentes reflexas. Por conta da sua descaracterização (tropicalização e/ou - neste caso - continentalização), a rampa de nuvens não se forma com eficiência num gradiente vertical, mas sim horizontal, formando sistemas de nuvens que provocam precipitação por várias horas e até mesmo dias. A intensidade destes sistemas pode variar, pois a produção da precipitação depende da disponibilidade de água (em formato de vapor e/ou microgotículas, via evaporação) que possa (retro)alimentar esses sistemas (MONTEIRO, 1969, 1971; NIMER, 1979; SANT'ANNA NETO, 2005; ARMOND, 2014).

\section{DA CLIMATOLOGIA GEOGRÁFICA À gEOGRAFIA DO CLIMA}

Como subcampo de conhecimento desenvolvido entre a Meteorologia e a Geografia, em sua gênese (MENDONÇA; DANNI-OLIVEIRA, 2007), alguns autores consideram que a Climatologia durante anos incorreu no estudo da atmosfera de forma estática (BARROS e ZAVATTINI, 2009; ZAVATTINI e BOIN, 2013). O abuso de técnicas estatísticas e outros artifícios matemáticos por pesquisadores pioneiros como Hann e Köppen refletiam a concepção de Climatologia como o estudo dos elementos meteorológicos que caracterizam o estado médio da atmosfera sobre determinado lugar.

Criticado por Sorre, o estudo dos climas sofreu mudanças substanciais, inaugurando-se outra forma de se estudar a atmosfera (ZAVATTINI; BOIN, 2013). Sorre não desprezava a média e a estatística. Ele apenas considerava 
que a sucessão dos tipos de tempo expressaria de forma global a variação do clima. É a partir dessa sucessão dinâmica que o geógrafo compreende os mecanismos de constituição dos climas. Ao sumarizar os fundamentos da Climatologia Geográfica, Sant'Anna Neto (2001a) apontou suas bases:

1) Desprezo dos valores médios e a utilização de dados reais, em escala diária, em proveito de uma minuciosa análise da variação dos elementos do clima;

2) A escolha de períodos - padrão (anual, estacional, mensal e episódico) que seriam capazes de fornecer um quadro dinâmico das situações concretas, demonstrando a amplitude de ocorrência dos tipos de tempo habituais, ao lado daqueles afetados por irregularidades na circulação com capacidade de produzir situações adversas.

Tributário de Sorre, a crítica às noções separativas e estáticas de Clima constitui-se em ponto forte na proposta de Climatologia Geográfica. Apesar de reconhecer a importância da utilização dos valores médios em estudos sobre variabilidade, o autor reafirma a centralidade dos dados reais em escala diária. Como se fossem tempos (musicais) constituintes de um ritmo (também musical) (MONTEIRO, 2001), a decomposição dos elementos da atmosfera em dados, colocados lado a lado no gráfico de análise rítmica, permite aliar a climatologia separativa e estática à climatologia dinâmica em uma análise em movimento.

Ao conferir importância à utilização dos valores "reais" dos elementos do clima, as análises regionais a partir de uma série histórica de dados demandava a escolha de anos representativos das condições habituais e mesmo excepcionais. Inicialmente escolhidos arbitrariamente e, posteriormente, com a utilização de técnicas estatísticas, Monteiro (1969) propôs a escolha de anospadrão representativos para estudo do ritmo climático de determinada localidade.

3) A utilização das cartas sinóticas de superfície como subsídio à identificação dos tipos de tempo, possibilitando a relação entre a circulação atmosférica regional com as manifestações individualizadas localmente;

A influência da meteorologia dinâmica trazida por Serra (1941, 1970a, 1970b, 1971), da chamada escola escandinava, permitiu a base para a análise dos sistemas atmosféricos na América do Sul. As cartas sinóticas, aliadas aos demais dados meteorológicos de superfície, cumpriram papel fundamental na identificação da gênese dos fenômenos em movimento.

4) A elaboração de um ciclo evolutivo da penetração da Massa Polar Atlântica, por considerar a sua presença (ou sua ausência) como o elemento fundamental, composto de três momentos: o prenúncio, avanço e domínio;

Para Nimer (1979), as massas que deixam a Antártica penetram pelos oceanos, local no qual sofrem processo de aquecimento e adquirem umidade. Esses elementos a tornam instável e, quando invade o continente sul americano pode seguir duas trajetórias, orientadas pela orografia. A primeira, a oeste dos Andes, e a segunda, sob a forma de grandes anticiclones a leste da cordilheira. 
No caso das invasões a oeste dos Andes, os ventos frios da massa polar se encontram com os ventos quentes tropicais continentais, constituindo uma zona chamada de Frente Polar Pacífica. Na segunda trajetória, a descontinuidade térmica advinda do encontro dos ventos frios da massa polar com os ventos quentes do sistema tropical constitui a Frente Polar Atlântica - FPA (NIMER, 1979).

Ainda que esteja redefinida a origem das massas polares - oriundas do Oceano Pacífico, da depressão do mar de Weddel, diferenciadas apenas pela sua origem latitudinal -, a questão que se coloca é a da consistência do ar polar na formação de frentes e, consequentemente, na gênese das chuvas.

Em estudo pioneiro sobre as chuvas na fachada sul-oriental do Brasil, Monteiro (1969) determina o inverno, na realidade brasileira tropical, a partir da relação entre temperatura e pluviosidade advindas da Frente Polar Atlântica. Após realizar a análise rítmica, o autor identificou que a área de maior atuação (habitual) da Frente Polar Atlântica seria na fronteira entre Rio Grande do Sul e Santa Catarina. Em casos de maior homogeneidade e ímpeto do ar polar, as perturbações frontais avançam e ocorrem em latitudes tropicais. Em caso de fraqueza de atividade polar e maior participação do ar tropical atlântico, a atuação da Frente Polar se restringe a latitudes mais elevadas.

Considera-se que as características que possibilitam ou não a penetração da Massa Polar Atlântica se reveste de importância fundamental na dinâmica atmosférica do Brasil, sobretudo do centro-sul. Da homogeneidade ou da pouca estruturação do ar polar atlântico resulta a intensidade e frequência dos principais sistemas geradores das chuvas no sul-sudeste. A teoria da frente polar (BJERKNES e SOLBERG, 1922) a coloca como protagonista e determinante da dinâmica atmosférica nessa região do país.

5) A análise da sequência e encadeamento dos tipos de tempo, na busca do entendimento das variações locais dentro de um quadro regional, marcado pelas características e influências dos fatores geográficos

Os dados atmosféricos em superfície, as informações sobre a cobertura vegetal e o relevo, em relação às cartas sinóticas e demais informações climáticas, se complementam e devem auxiliar para a produção de uma análise baseada na gênese dos fenômenos atmosféricos e sua atuação sobre determinado lugar. Nesse caso, as informações de superfície são fundamentais. A mensuração dos elementos e sua comparação com outros atributos geográficos de análise permite a visualização espacial da dinâmica climática.

6) E, por fim, a tentativa de classificação climática, em bases genéticas e dinâmicas, a partir dos índices de participação dos sistemas atmosféricos atuantes e suas respectivas repercussões no espaço geográfico.

Identificar quais os sistemas que atuam sobre determinado lugar, tanto em seu padrão habitual quanto excepcional, se reveste de caráter geográfico. Saber se é a Frente Polar Atlântica - FPA, ou a Frente Quente - FQ, ou mesmo complexos conjuntos convectivos como a Zona de Convergência do Atlântico Sul - ZCAS, os produtores de chuvas que deflagram transtornos faz parte da essência da Climatologia Geográfica. Para Monteiro (1991), são as 
excepcionalidades que, por excelência, descortinam a Geografia do fenômeno climático.

A partir destes pressupostos, Monteiro (1971) elaborou o gráfico de análise rítmica, que influenciou diversos pesquisadores em Climatologia até os dias atuais ao buscar retratar que, na escala do ritmo, os elementos atmosféricos influenciam mais diretamente o cotidiano dos grupos sociais.

A consolidação da teoria crítica e a centralidade da perspectiva da produção do espaço geográfico no Brasil consistiram influência importante nos estudos climáticos. Assim, tratar da gênese dos fenômenos atmosféricos em função das suas influências a partir de um espaço socialmente produzido é o que dá sentido à proposta da Geografia do Clima.

A crítica do tripé do ritmo climático - ação antrópica - impacto ambiental fez com que a produção de conhecimento sobre o clima se transformasse em, pelo menos, duas dimensões: a dimensão ontológica (a saber, aquilo que existe para ser estudado em uma abordagem geográfica do clima) e a dimensão epistemológica (a redefinição do conteúdo das palavras empregadas, garantindo uma ressignificação de uma série de conceitos e o surgimento de outros, como vulnerabilidade e risco). Ao assumir como ponto de partida dos estudos do fenômeno climático na Geografia o espaço socialmente produzido (SANT'ANNA NETO, 2001b, 2008, 2013), por conseguinte ocorrem estes dois giros, ontológico e epistemológico, que caracterizam a Geografia do Clima (ARMOND, 2014).

\section{EXCEPCIONALIDADES DAS CHUVAS: ENTRE EVENTOS E EPISÓDIOS}

Os limiares para a definição dos eventos intensos e/ou extremos de chuva são dos mais variados na literatura, com a utilização de diferentes modelos e técnicas (GENOVEZ; ZUFFO, 2000). De natureza fundamentalmente quantitativa, os limites têm sido definidos em termos de altura de precipitação, como 50mm em 6h (KONRAD II, 1997); 300\% da chuva acima da média diária (CHAVES E CAVALCANTI); $20 \%$ da chuva prevista para toda a estação precipitada em 24h (CARVALHO et al, 2002).

Sobre o estudo de eventos extremos na Geografia, esta relação puramente quantitativa se complexifica, e as excepcionalidades passam a ser analisadas não apenas em termos percentuais, quantitativos ou de limiares, mas em função da relação das chuvas com os impactos deflagrados.

Vicente (2004), que delimitou $50 \mathrm{~mm}$ precipitados em $24 \mathrm{~h}$ como limiar, constatou que as áreas periféricas e favelas eram mais afetadas por episódios de chuva intensa. Os bairros classe média também foram afetados, mas a natureza do dano foi diferente. Enquanto camadas populares apresentavam perdas materiais e óbitos, bairros de população mais abastada sofreram com alagamentos e inundações, com poucas perdas materiais.

Resultados semelhantes foram encontrados em Silveira (2007), Lima (2012) e Colischonn (2009), que encontraram casos de inundações deflagrados com limiares inferiores a $30 \mathrm{~mm}$ em $24 \mathrm{~h}$. 
Gonçalves (2003) e Oliveira e Hermann (2005), sinalizaram a importância de se considerar a dinâmica urbana nos episódios de inundação, encontrando impactos com chuvas inferiores a $40 \mathrm{~mm}$ em $24 \mathrm{~h}$.

A relação entre chuva e inundações urbanas foi estudada no Rio de Janeiro por Brandão (2005). Segundo a autora, sua posição latitudinal interfere diretamente nos sistemas geradores das chuvas, uma área transicional de conflito entre sistemas polares e intertropicais. Os maciços litorâneos também interferem diretamente no regime de chuvas da cidade, e justamente por conta da sua situação tropical, eventos pluviais intensos atingem com frequência a cidade.

Considera-se que a ocorrência de eventos de chuva extrema (acima da média ou dos padrões da dinâmica do local em análise) desencadeia uma série de transtornos, sobretudo em áreas urbanas com alta impermeabilização do solo e descaracterização das bacias, nas proximidades de córregos e rios.

Porém, uma análise que parte da perspectiva teórica da Geografia do Clima (SANT'ANNA NETO, 2001a, 2008) demanda um olhar não só à quantificação dos valores de precipitação. Eles são importantes e necessários para análises dos impactos. Contudo, no campo da Geografia eles precisaram necessariamente passar por uma transformação qualitativa e politizadora, que sinaliza a importância de se considerar o espaço geográfico em sua produção contraditória e desigual na análise dos eventos extremos - ao menos na perspectiva do impacto (sejam eles inundações, enchentes, alagamentos, deslizamentos ou demais transtornos como acidentes de trânsito e afins).

Essa discussão está presente de forma fundamental em Berezuk (2012), que traz a dimensão da relação entre a chuva como fenômeno físico e as diferentes formas através das quais se modifica a análise deste fenômeno principalmente quando da necessidade de se empreender uma perspectiva geográfica sobre ele. Para o autor,

a chuva não fica limitada ao processo físico da precipitação dentro de um ciclo sistêmico de troca de matéria e energia. Ela também se constitui como um fator de características determinísticas, ora entendida como possibilidade e condição de domínio e conhecimento do território, ora como fundamento da perpetuação regional da existência de uma dada sociedade, com um significado essencialmente geopolítico (BEREZUK, 2012).

Assim, são significativas as diferenças entre o que se pode considerar enquanto extremos meteorológicos - aqueles em que elevados totais de chuva são precipitados num tempo relativamente curto, articulando a relação direta entre intensidade e frequência -, e os episódios, que relativizam a produção dos eventos enquanto natureza apropriada na produção do espaço.

A partir disso, foram caracterizados enquanto eventos que desencadearam - e que não desencadearam e/ou tiveram qualquer associação com - impactos que puderam ser identificados no espaço urbano. Estabeleceuse, assim, a diferença consciente e deliberada entre os eventos extremos (de natureza matemático-estatístico ou valores que ultrapassam os padrões 
climáticos habituais), e os episódios (de natureza geográfica ou de análise que prioriza a observação de impactos).

\section{RESULTADOS E DISCUSSÕES}

No mundo tropical, eventos de chuva extrema podem ser detectados em períodos que apresentem totais de chuva dentro dos padrões habituais ou mesmo naqueles considerados secos.

A análise dos dados de precipitação pluviométrica acima de $20 \mathrm{~mm}$ em 24h nos anos de 1999, 2006, 2010, 2011 e 2012, permitiram a identificação de 43 (quarenta e três) excepcionalidades. Destas, 27 (vinte e sete) foram caracterizadas como eventos extremos (aqueles que não deflagraram qualquer tipo de repercussão e/ou impacto) e 16 delas foram caracterizadas como episódios (que deflagraram impactos noticiados em jornal).

Em nível de detalhamento anual, todos os anos (com exceção do ano de 2010) apresentaram maior número de eventos extremos do que de episódios extremos (figura 3).

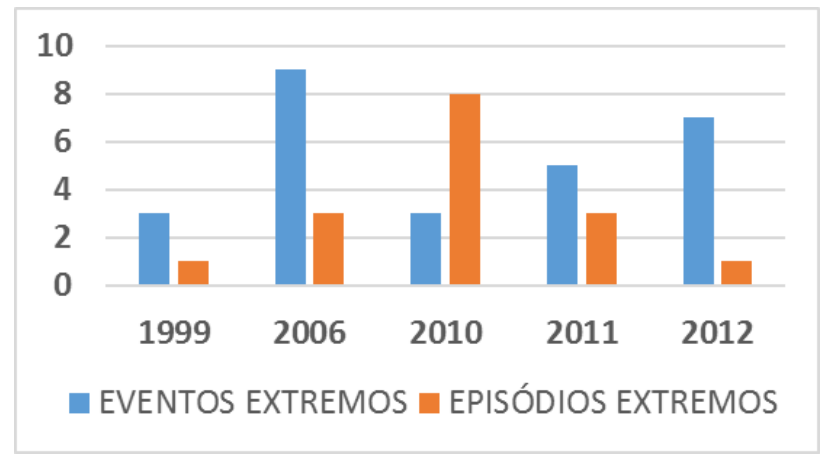

Figura 3: Eventos e episódios por ano analisado (1999, 2006, 2010, 2011 e 2012).

Fonte: Fundação AlertaRio e Jornal O Extra; Elaboração: Autores

O ano de 1999, classificado como excepcionalmente seco, apresentou os menores números de eventos e de episódios ( 3 e 1 , respectivamente) de chuvas intensas. O ano habitual (2006) apresentou quantidade intermediária de eventos e episódios (9 e 3, respectivamente), com o ano de 2010 (ano excepcionalmente chuvoso) apresentando o maior número de episódios da série (8 episódios e 3 eventos). Os anos de 2011 e 2012 apresentaram a mesma tendência - maior número de eventos que de episódios, com respectivamente 5 e 7 eventos e 3 e 1 episódios.

Em linhas gerais, a existência de dias com precipitação acima de $20 \mathrm{~mm}$ não necessariamente significa a certeza da deflagração de episódios. Nesse sentido, a precipitação e sua intensidade são fatores que devem ser considerados na análise. Entretanto, não são fatores determinantes para a ocorrência de impactos. Assim, revisão de literatura sobre eventos extremos, principalmente aquela oriunda do campo da Geografia, mostrou apontamentos e desafios importantes para o estudo geográfico das excepcionalidades. 


\section{ANÁLISE TEMPORAL I: OS SISTEMAS ATMOSFÉRICOS E AS EXCEPCIONALIDADES EM SEUS TOTAIS}

Os eventos extremos descritos e analisados, que obedeceram apenas o estabelecimento de limiares quantitativos $(20 \mathrm{~mm})$, não apresentaram correspondência com consequências relacionadas a transtornos e impactos no espaço urbano do município do Rio de Janeiro.

A análise quantitativa dos sistemas geradores dos eventos resultou na ocorrência, nos cinco anos analisados e dentro de um total de 27 eventos: 18 eventos gerados pela Frente Polar Atlântica; 4 pela Zona de Convergência do Atlântico Sul; 2 pela Frente Estacionária, 1 pela Frente Quente, 1 pela Zona de Convergência de Umidade e 1 pela Instabilidade Tropical (figura 4).

Em termos percentuais, a FPA respondeu por mais de $66 \%$ do total de eventos extremos. No caso da contabilização dos sistemas associados à ocorrência da FPA (FE, FQ, FR), pode-se considerar que ela somou aproximadamente $81,4 \%$ de participação na produção de eventos extremos.

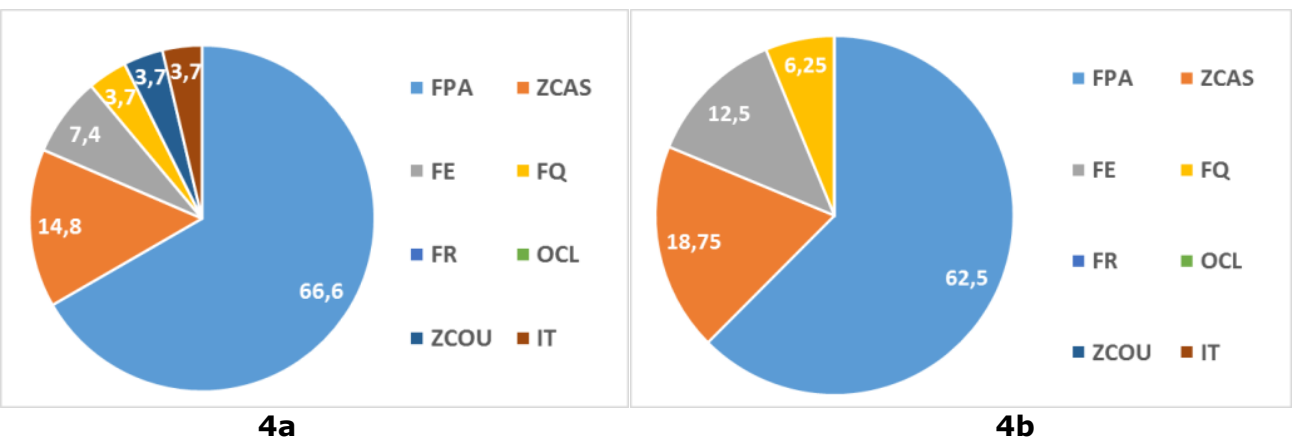

Figuras 4a e 4b: Porcentagem de sistemas atmosféricos produtores de eventos extremos (3a) e de episódios extremos (3b) de chuva no município do Rio de Janeiro Fonte: Fundação AlertaRio, CPTEC/INPE, DHN/Marinha do Brasil; Elaboração: Autores

É importante ressaltar também a importância da ZCAS na produção de eventos extremos de precipitação. Respondendo por $14,8 \%$, este sistema atmosférico tem sua origem atrelada à FPA, mas não é caracterizada apenas por ela, conforme discutido anteriormente. O seu caráter de permanência ( 3 a 5 dias), com chuvas contínuas na área em que se situa sob sua banda de nebulosidade, pode fazer com que a saturação do solo e das redes de drenagem ocasionem inundações e alagamentos, sobretudo em grandes centros urbanos.

A maior parte das chuvas extremas que ocorreram nos anos em análise foi desencadeada por sistemas atmosféricos regionais. A FPA e sistemas associados (FE, FQ e mesmo a ZCAS), foram responsáveis por mais da metade das chuvas.

No caso dos episódios extremos, verificou-se que a maior parte delas foi gerada pela FPA, com 62,5\%, seguida da ZCAS (18,75\%), Frente Estacionária $(12,5 \%)$ e Frente Quente $(6,25 \%)$. Caso se considere sistemas como a FE e a FQ como também originários a partir do avanço do ar polar em direção às baixas latitudes, a FPA acaba por responder por $81,25 \%$ das chuvas 
que deflagraram algum tipo de transtorno no espaço urbano do município do Rio de Janeiro.

Em uma análise comparativa, ambas as excepcionalidades apresentaram-se produzidas pelos mesmos sistemas atmosféricos. No caso dos episódios, a participação da ZCAS e da FE, apesar de superior quando em comparação à análise dos eventos, não foi significativa para qualificar alguma diferença na deflagração dos impactos. Ou seja, os mesmos sistemas atmosféricos produziram chuvas acima dos limiares propostos para análise e que não deflagraram transtornos e, também, que deflagraram transtornos.

Em geral, os resultados confirmam o que foi apresentado por Monteiro (1969, 1971), Conti (1975), Nimer (1979), Sant'Anna Neto (2005) e Armond $(2014,2016)$ sobre os sistemas atuantes na Região Sudeste e no Rio de Janeiro em especial: sua localização transicional entre os sistemas polares e os sistemas tropicais faz com que a natureza da precipitação tenda a ser, majoritariamente, frontal, caracterizada pela participação da Frente Polar Atlântica - FPA na produção das chuvas que deflagram excepcionalidades na área de estudo.

\section{ANÁLISE TEMPORAL II: OS SISTEMAS ATMOSFÉRICOS E AS EXCEPCIONALIDADES EM SUA SAZONALIDADE}

Na análise mensal, com ocorrência de excepcionalidades (gráficos $4 a$ e 4b), verificou-se que a maior parte dos sistemas atmosféricos deflagradores de transtornos produziu precipitação nos meses da estação chuvosa.

Nos eventos extremos (figura 5a) houve destaque para o mês de Janeiro, com 4 ocorrências na série analisada. O mês de Março também apresentou elevado número de ocorrências, com 3, empatado com o mês de Setembro. Ainda que não tenha se configurado muitas ocorrências anuais neste mês, abril registrou dois eventos no mesmo mês. Os meses de menor frequência são maio, junho e julho, que coincide com o trimestre menos chuvoso.

De forma geral, a situação latitudinal e costeira do Rio de Janeiro, atrelada a orografia, são importantes elementos que possibilitam a ocorrência de eventos de chuva extrema durante o ano inteiro. Porém, nem sempre as chuvas extremas podem se configurar enquanto elementos deflagradores de episódios extremos (ou seja, aqueles que geram repercussões no espaço urbano).

Já no que se refere aos episódios extremos (aqueles que tiveram algum impacto deflagrado), o maior número de episódios no ano de 2010 também foi ocasionado pela ocorrência da FPA, que só neste ano foi responsável por 5 episódios de chuva extrema. O ano de 2011 teve 2 de seus episódios gerados a partir da FPA. Em segundo lugar em frequência, a ZCAS esteve presente nos anos de 2006, 2010 e 2011 (Figura 5b). 


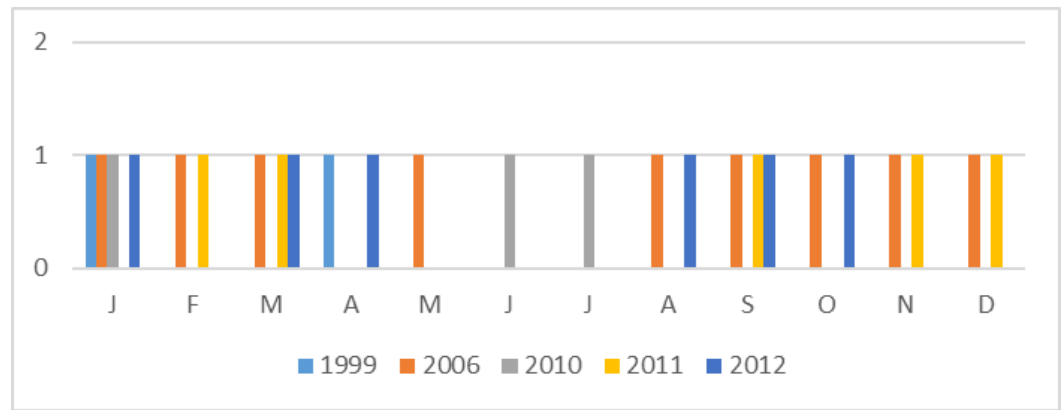

$5 a$

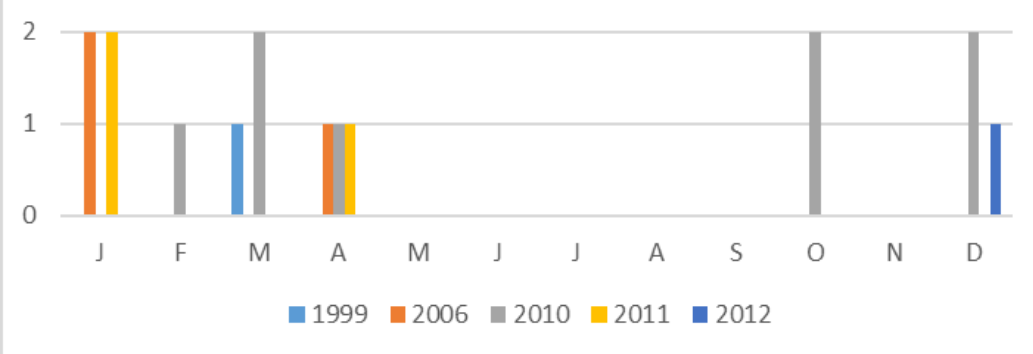

5b

Figuras 5a e 5b: Distribuição mensal dos excepcionalidades - eventos (4a) e episódios (4b) em cada ano da série analisada

Fonte: Fundação AlertaRio, CPTEC/INPE, DHN/Marinha do Brasil; Elaboração: Autores.

Em uma análise mensal, constatou-se que os meses da estação chuvosa (de outubro a março) tiveram tipos de tempo produtores de extremos que deflagraram episódios. O mês de abril se apresentou como o que possuiu maior número de ocorrências nos cinco anos amostrados - em 2006, 2010 e 2011. Em segundo, com duas ocorrências, estão os meses de janeiro, março e dezembro. Fevereiro e outubro tiveram apenas um episódio cada, no ano de 2010.

Verificou-se que, apesar da existência da possibilidade de ocorrência de eventos extremos durante todos os meses do ano, é nos meses da estação chuvosa que os episódios são desencadeados. Ressalta-se a importância do mês de abril na observação de chuvas extremas em termos de eventos e episódios. Seu caráter transicional, de período de últimas ocorrências de precipitações do alto verão oriundas da FPA, pode ser afetado por teleconexões como ENOS, que modulam as chuvas e interferem na sua intensidade.

\section{ANÁLISE ESPACIAL I: AS EXCEPCIONALIDADES E A INTENSIDADE DAS CHUVAS EM SUA ESPACIALIDADE}

A distribuição espacial das excepcionalidades também merece atenção especial dentro na análise, pois é a partir dela que pode se observar o hibridismo elementos, fatores e produção do espaço geográfico na localização dos episódios extremos.

No caso dos eventos extremos (figura 6a), é possível observar a concentração de totais pluviométricos mais elevados nas áreas próximas aos grandes maciços da cidade (Maciço da Tijuca e Maciço da Pedra Branca), sobretudo à barlavento, na vertente orientada em direção à linha de costa. As áreas situadas ao fundo da Baía de Guanabara, a leste, também apresentam 
maior porcentagem da sua chuva situada nas faixas acima de $60 \mathrm{~mm} / 24 \mathrm{~h}$. Já os pluviômetros situados na vertente a sotavento dos maciços, apresentam maior porcentagem de chuva nas faixas abaixo de $40 \mathrm{~mm} / 24 \mathrm{~h}$.

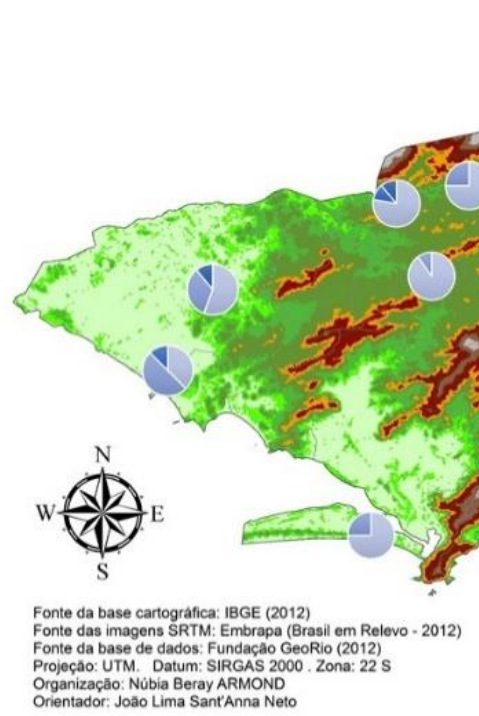

Todor. Joama SantAnna Neto

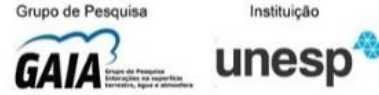

\section{LEGENDA}

$\square$ Telepluviômetros Hipsométrico Cota $(m)$

$\square 0-3,6$ $\square, 7-5,9$ $\square 6-7,4$ $\square 7,5-9,7$ $9,8-13$ - $14-19$ $20-28$ $\square 29-43$ 44. 66 67.100
$67-100$
$110-160$ -170-230 $240-350$ $360-470$ $\square \quad 480-630$ $\square 640-810$

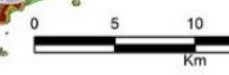
$\square 820-1.000$

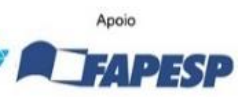

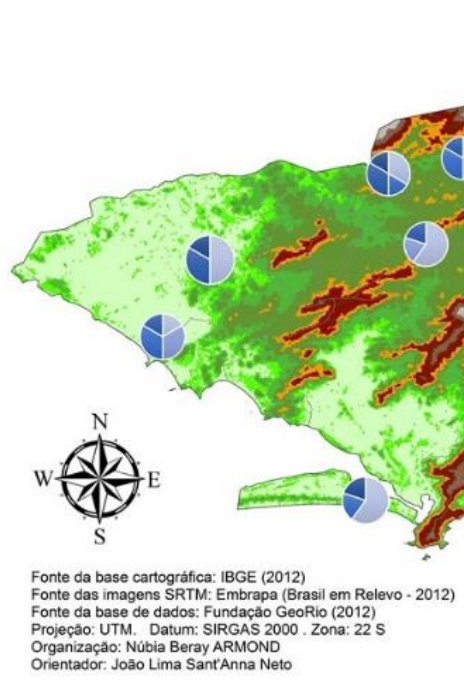

Orientador: João Lima Sant'Anna Neto
$6 a$

Figuras 6a e 6b: Mapas da intensidade das chuvas durante os eventos (2a) e episódios (2b) sobre mapa hipsométrico. Os círculos em tons de azul representam a porcentagem dos dias em relação a intensidade das chuvas, que varia dos tons mais claros $(20 \mathrm{~mm}$ em 24h) aos tons mais escuros (acima de $100 \mathrm{~mm}$ em 24h).

Fonte: Fundação AlertaRio, CPTEC/INPE, DHN/Marinha do Brasil, Embrapa; Elaboração: Autores. 
A exceção situa-se ao norte, em postos situados a sudeste do Maciço do Gericinó (que não aparece integralmente no recorte realizado na figura $6 a$, apenas um pequeno fragmento, mas que pode ser visto na figura 1 ). O posto que apresenta, na composição da sua precipitação, porcentagem considerável na faixa acima de $60 \mathrm{~mm} / 24 \mathrm{~h}$ situa-se exatamente no topo do Maciço da Tijuca, o que denota, novamente, a influência da orografia, da maritimidade e da orientação das vertentes na distribuição espacial da precipitação pluviométrica.

No que se refere aos episódios (figura 6b), observou-se um incremento nas faixas de intensidade mais elevadas, com a maioria dos postos apresentando pelo menos $1 / 4$ da composição da sua precipitação nos episódios em chuvas acima de $100 \mathrm{~mm}$. O padrão espacial da distribuição dessa intensidade se altera, demonstrando uma maior similaridade espacial da precipitação. Se, nos eventos, os postos que apresentavam composição da sua precipitação acima de $40 \mathrm{~mm} / 24 \mathrm{~h}$ encontravam-se na vertente litorânea a barlavento dos maciços, no caso dos episódios, este padrão apresenta diferenças.

Para os eventos, o padrão de distribuição espacial das elevadas intensidades de precipitação é mais discreto e coeso, inerentemente ligado à influência da orografia. Já no caso dos episódios, a configuração não apresenta essa homogeneidade, obedecendo a uma distribuição da intensidade das chuvas, em geral, mais abrangente. Ocorre que a maioria dos postos, no caso dos episódios, apresenta precipitações acima de $100 \mathrm{~mm}$, independente de sua situação espacial.

Destaca-se, novamente, que as diferenças entre os eventos e episódios consistiram basicamente no processo posterior ao da precipitação pluviométrica: sua diferenciação se dá na deflagração (ou não) de transtornos de variadas ordens. Assim, pode parecer evidente inferir que os episódios apresentaram a ocorrência de chuvas mais intensas nos postos pluviométricos do que os eventos. Portanto, a deflagração de impactos pode ser relacionada proporcionalmente à intensidade das chuvas.

Porém, é necessário lembrar que, no caso dos episódios, a distribuição espacial da composição das chuvas de elevada intensidade em cada posto pluviométrico apresentou padrão diferenciado. Pelo contrário, ocorreu uma maior similaridade espacial das faixas de elevada intensidade de precipitação, demandando análises mais robustas (com a utilização de técnicas de agrupamento, por exemplo) para definir agrupamentos espaciais.

Enfim, já que o padrão espacial encontrado foi difuso, mais regionalizado, pode-se também depreender que as chuvas deflagradoras de episódios, intensas em todos os postos, afetam de forma significativa todas as localidades no município do Rio de Janeiro que apresentaram elevada intensidade. Porém, uma análise pormenorizada e qualitativa dos episódios demanda o acionamento de outras chaves explicativas destes acontecimentos.

\section{OS EPISÓDIOS EXTREMOS E OS LOCAIS AFETADOS}

Sobre os locais de ocorrência dos episódios, os bairros mais citados foram a Praça da Bandeira e a Tijuca, impactados por 5 episódios cada. A Barra 
da Tijuca, Bonsucesso e Centro apresentaram 4 citações cada, seguidos de Jacarepaguá, Maracanã, Olaria e Penha, com 3 citações cada (figura 7).

Verifica-se a predominância de citações e, por conseguinte, da ocorrência de episódios nos bairros da zona norte (Bonsucesso, Maracanã, Praça da Bandeira, Tijuca, Jacarepaguá, Olaria, Penha) e da zona oeste (Barra da Tijuca).

A importância para a análise das chuvas que considere a orografia, a situação costeira e latitudinal é fundamental para a compreensão dos episódios extremos no município do Rio de Janeiro. Expressão disso é a distribuição espacial dos locais de ocorrência de episódios de alagamento.

A quantidade de citações de Jacarepaguá e Barra da Tijuca representam a importância dos maciços como divisores de água, com parte da convergência do fluxo da precipitação sendo direcionado para a baixada de Jacarepaguá. Este bairro é historicamente conhecido no Rio de Janeiro pela ocorrência de alagamentos, tendo sofrido, no ano de 1996, uma enchente histórica, que destruiu uma série de equipamentos urbanos, casas, comércio popular e afins.

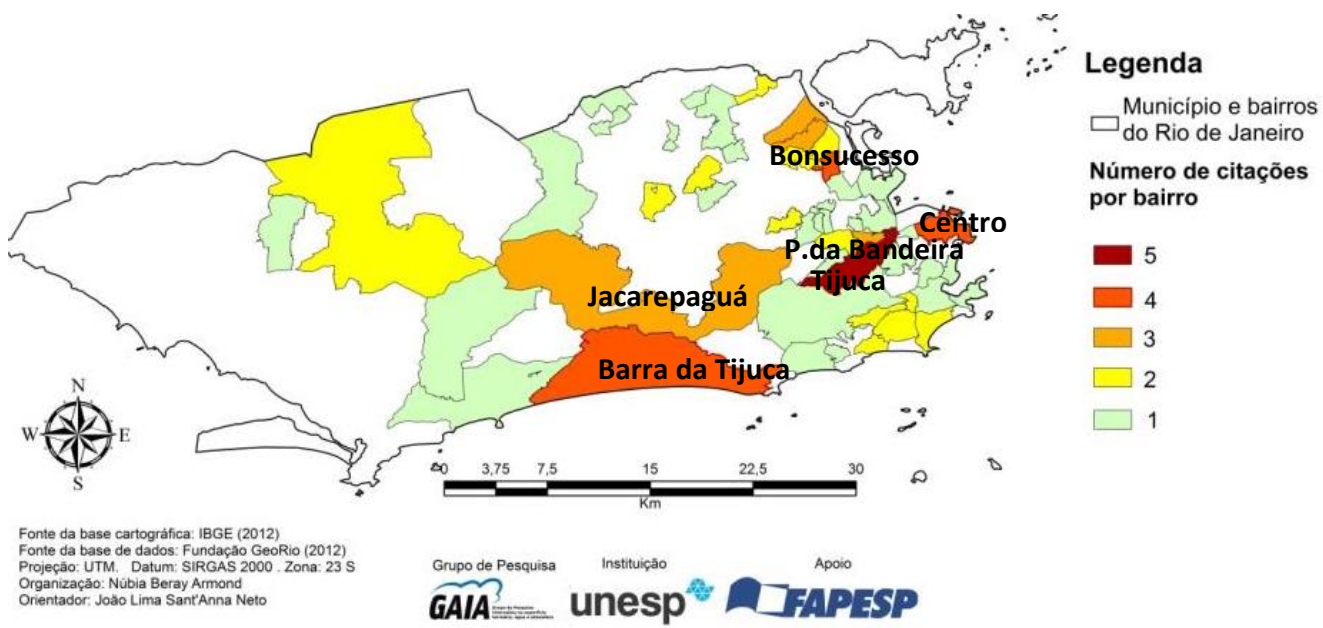

Figura 7: Bairros do município do Rio de Janeiro, segundo quantidade de citações no Jornal O Extra

Fonte: Jornal O Extra; Elaboração: autores.

A maior parte dos bairros citados que se localizam na zona norte, situase nos arredores do Maciço da Tijuca. Sua localização a barlavento, conforme verificado, produz em uma área de maior concentração de precipitação, enquanto, à sotavento, caracteriza-se uma zona de sombra de chuva. Ela é exemplificada através do menor número de dias de chuva e menores médias na série histórica.

Entretanto, é na sua área de sotavento que se concentra a maior parte dos episódios, o que caracteriza a importante interferência das modificações realizadas no sítio urbano no desencadeamento de episódios de alagamento no município (ABREU, 2006; COELHO, 2007; ANDREATTA et al, 2009). Parte considerável desses bairros consistia em áreas de manguezal, caracterizadas por solos hidromórficos (com elevado ou total grau de saturação, formando áreas alagadiças). Além disso, cabe ressaltar que essa é uma área de deságue de vários rios para a Baía de Guanabara, com a formação de estuários. A 
chegada de sedimentos finos (argilosos e siltosos) nesta localidade faz com que o solo seja altamente instável para edificações, demandando um maior grau de intervenção e sofisticação que, obviamente, não é de interesse do poder público na promoção da qualidade de vida dos vulneráveis residentes destas áreas de risco (SATTERTHWAITE et al, 2009).

\section{CONSIDERAÇÕES FINAIS}

Inicialmente, uma climatologia separativa e estática buscou compreender os padrões de cada elemento do clima na perspectiva da realização de classificações climáticas mais genéricas. Entretanto, a crítica de Max. Sorre a esse tipo de análise fez com que outras formas surgissem. Foi dessa crítica que surgiu a proposta da Climatologia Geográfica (MONTEIRO, 1969, 1971, 1991), que tem procurado compreender os elementos atmosféricos em sua dinâmica.

Mais recentemente, Sant'Anna Neto (2001a, 2001b, 2008) deslocou o eixo epistemológico da Climatologia na Geografia. A busca pelo que, do clima, interessa à ciência geográfica fez com que, sob as lentes da Geografia do Clima, as excepcionalidades fossem analisadas no estudo que se seguiu.

Os estudos sobre impactos das chuvas na cidade, sobretudo na Geografia, demonstraram que chuvas com intensidade reduzida também ocasionam impactos no urbano. E que nem toda a chuva intensa pode deflagrar impactos.

Por conta da disponibilidade de dados atrelada ao que já foi estudado e discutido na literatura de eventos extremos na Geografia, abordaram-se inicialmente os extremos em sua escala diária (acima de $20 \mathrm{~mm}$ de chuva em 24h) como passíveis de deflagração de impactos. Depois, com a aquisição de dados qualitativos mais recentes, tomou-se uma equação de chuva extrema em escala horária como considerável definidora de limiares de precipitação que pudessem, potencialmente, gerar impactos no território.

Assim, dentre os anos da série histórica, o ano padrão seco apresentou menor quantidade de eventos extremos, enquanto o habitual apresentou mais eventos, porém, com menor intensidade. Os anos chuvosos apresentaram elevado número de eventos de grande magnitude.

Com a análise dinâmica dos mecanismos geradores destas chuvas e a consulta qualitativa da ocorrência de impactos, optou-se por tomar dois tipos de extremos como passíveis de análise. O primeiro, "extremo meteorológico", é o que se chama aqui de "evento extremo": as chuvas estatisticamente acima dos valores habituais. As chuvas que deflagraram impactos foram analisadas dentro de uma segunda perspectiva: a dos episódios extremos - aqueles que repercutiram no espaço urbano.

Concluiu-se que a maior parte (70\% de eventos e $62,5 \%$ dos episódios) das excepcionalidades foram deflagradas pela atuação da Frente Polar Atlântica - FPA, seguidos da Zona de Convergência do Atlântico Sul - ZCAS (13,4\% e $18,75 \%$, respectivamente) e da Frente Estacionária - FE $(6,6 \%$ dos eventos e $12,5 \%$ dos episódios). A situação latitudinal do Rio de Janeiro, localizado numa área de transição entre o ar polar mais frio e seco e o ar tropical quente e úmido, faz com que o sudeste brasileiro possua a característica transicional. 
Com relação às condições climáticas que deflagraram a ocorrência dos impactos, a análise permitiu atestar a complexidade da questão. Os resultados obtidos demonstraram que a deflagração de repercussões não se relaciona de forma linear com as chuvas de elevada intensidade. Em outras palavras: nem todo evento extremo desencadeia episódios. Porém, quase todos os episódios foram desencadeados por eventos extremos. Assim, a intensidade das chuvas não é fator determinante para a ocorrência de repercussões.

A identificação dos episódios extremos se deu pela sua localização em dois eixos: no primeiro, as inundações foram mais noticiadas em bairros que apresentam condições geomorfológicas/fisiográficas desfavoráveis, como a baixada de Jacarepaguá, um dos bairros mais citados. O segundo eixo apresentou os bairros que tiveram maior intervenção em seu sítio urbano, como aterramento de manguezais, de áreas estuarinas e canais, fenômeno realizado desde a ocupação portuguesa no Rio de Janeiro para gerar incorporação de áreas continentais para exploração econômica (imobiliária, comercial ou industrial).

Os frutos deste processo são as diferentes naturezas dos danos que são deflagrados em cada local a partir das chuvas intensas. Em verdade, as chuvas servem como mecanismo de desvendamento da produção do espaço urbano do Rio de Janeiro em seu processo histórico. Os locais de alagamento são os registros de uma história que desconsiderou as características da materialidade de seu chão. Em outras palavras, tenta se reinventar e reinventar o espaço, com ares de novidade - característica da modernidade. O resultado é que, de fato, no Rio de Janeiro, a natureza encontra a história. E as chuvas trazem à tona as várias naturezas de suas geografias.

\section{AGRADECIMENTOS}

A FAPESP e ao CNPq, que viabilizaram a realização deste estudo através de concessão de bolsa de estudos no país e no exterior.

A Lindberg Nascimento Junior, Vinicius Carmelo e Karime Fante, pelas críticas e sugestões.

Aos avaliadores que, através de seus pareceres, possibilitaram melhorias para este artigo através de críticas e apontamentos realizados de forma respeitosa e pedagógica, com o intuito de fazer avançar a ciência geográfica do Clima.

\section{REFERÊNCIAS BIBLIOGRÁFICAS}

ABREU, Maurício de Almeida. A cidade, a montanha e a floresta. In: ABREU, Mauricio de Almeida (org). Natureza e sociedade no Rio de Janeiro. Rio de Janeiro: Biblioteca Carioca, 1992.

ABREU, Maurício de Almeida. Evolução urbana do Rio de Janeiro. Rio de Janeiro: Instituto Pereira Passos, 2006.

ANDREATTA, Verena; CHAVARI, Maria Pace; REGO, Helena. O Rio de Janeiro e sua orla: história, projetos e identidade carioca. Coleção Estudos Cariocas, n. 20091201. Rio de Janeiro: Instituto Pereira Passos, 2009. 
ARMOND, Núbia Beray. Entre eventos e episódios: as excepcionalidades das chuvas e os alagamentos no espaço urbano do Rio de Janeiro. Dissertação (Mestrado). Programa de Pós-Graduação em Geografia. Presidente Prudente: FCT/UNESP, 2014.

ARMOND, Núbia Beray. Sobre formas e processos na gênese das chuvas no município do Rio de Janeiro. In: SANT'ANNA NETO, João Lima; AMORIM, Margarete C. de Costa Trindade; SILVA, Charlei Aparecido (orgs). Clima e gestão do território. Jundiaí: Paco Editorial, 2016.

ARMOND, Núbia Beray; SANT'ANNA NETO, João Lima. Análise comparativa de técnicas estatísticas para definição de anos-padrão: o exemplo do Rio de Janeiro - RJ (1999-2010). Anais do XVIII Encontro Nacional de Geógrafos. São Luís: AGB, 2016.

BARROS, Juliana Ramalho; ZAVATTINI, João Afonso. Bases conceituais em Climatologia Geográfica. Revista Mercator, ano 8, n. 16, p. 255-261, 2009.

BEREZUK, A. G. Os milímetros são relevantes: apontamentos e reflexões sobre variabilidade pluvial e gestão de recursos hídricos. In: SILVA, C. A; FIALHO, E. S (Orgs). Concepções e ensaios da climatologia geográfica. Dourados. UFGD, 2012, p. $285-298$.

BJERKNES, J.; SOLBERG, H. Life cycle of cyclones and the Polar Front Theory of Atmospheric Circulation. Geophysisks Publikationer, 3, n. 1, p. 3-18, 1922.

BRANDÃO, Ana Maria de Paiva Macedo. Clima urbano e enchentes na cidade do Rio de Janeiro. In: GUERRA, Antonio José Teixeira; CUNHA, Sandra Baptista (orgs). Impactos ambientais urbanos no Brasil. $3^{a}$ edição. Rio de Janeiro: Bertrand Brasil, 2005.

CARVALHO, Leila; JONES, Charles; LIEBMANN, Brant. Extreme precipitation events in southeastern South America and large-scale convective patterns in the South Atlantic Convergence Zone. Journal of Climate, v. 15, p. 2377-2394, 2002.

CHAVES, Rosane e CAVALCANTI, Iracema. Eventos extremos de precipitação sobre o sul do Nordeste. In: Anais do CBMET, 2000.

COELHO, Victor. Baía de Guanabara: uma história de agressão ambiental. Rio de Janeiro: Casa da Palavra, 2007.

COLLISCHONN, Érika. Inundações em Venâncio Aires, RS: interações entre as dinâmicas natural e social na formação de riscos socioambientais urbanos. Tese (Doutorado). Programa de Pós-Graduação em Geografia. Florianópolis: UFSC, 2009.

CONTI, José Bueno. Circulação secundária e efeito orográfico na gênese das chuvas na região lesnordeste paulista. Série Teses e Monografias, n. 18. São Paulo: IG/USP, 1975.

DE MARTONNE, Emanuel. Problemas morfológicos do Brasil Tropical atlântico. Revista Brasileira de Geografia, ano 6, n. 2. Rio de Janeiro: IBGE, 1944.

FERNANDES, Nelson da Nóbrega. O rapto ideológico da categoria subúrbio. Rio de Janeiro: Apicuri, 2011. 
GALVÃO, Maria do Carmo Correa. Focos sobre a questão ambiental no Rio de Janeiro. In: ABREU, Mauricio de Almeida (org). Natureza e sociedade no Rio de Janeiro. Rio de Janeiro: Biblioteca Carioca, 1992.

GENOVEZ, Abel Maia e ZUFFO, Antonio Carlos. Chuvas intensas no estado de São Paulo: estudos existentes e análise comparativa. Revista Brasileira de Recursos Hídricos, vol. 5, n. 3, p. 45-58, 2000.

GONÇALVES, Neyde. Impactos pluviais e desorganização do espaço urbano em Salvador. In: MENDONÇA, Francisco e MONTEIRO, Carlos Augusto de Figueiredo (orgs). Clima urbano. São Paulo: Contexto, 2003.

KONRAD II, Charles. Synoptic-scale features associated with warm season heavy rainfall over interior southeastern United States. Weather and Forecasting, v. 12, p. 557-571, 1997.

LIMA, Altieris Porfírio. Análise de impactos associados à precipitação na cidade de São Carlos - SP. Dissertação (Mestrado). Programa de Pós-Graduação em Geografia. Presidente Prudente: FCT/UNESP, 2012.

MENDONÇA, Francisco e DANNI-OLIVEIRA, Inês Moresco. Climatologia: noções básicas e climas do Brasil. São Paulo: Contexto, 2007.

MONTEIRO, Carlos Augusto de Figueiredo. A frente polar atlântica e as chuvas de inverno na fachada sul-oriental do Brasil. Série Teses e Monografias, n. 1. São Paulo: IG-USP, 1969.

MONTEIRO, Carlos Augusto de Figueiredo. Análise rítmica em Climatologia problemas da atualidade climática em São Paulo e achegas para um programa de trabalho. Climatologia, vol. 1, n. 1. São Paulo, 1971.

MONTEIRO, Carlos Augusto de Figueiredo. Clima e excepcionalismo. Conjecturas sobre o desempenho da atmosfera como fenômeno geográfico. Florianópolis: Editora da UFSC, 1991.

MONTEIRO, Carlos Augusto de Figueiredo. De tempos e ritmos: entre o cronológico e o meteorológico para a compreensão geográfica dos climas. Geografia, Rio Claro, v. 26, n. 3, p. 131-154, 2001.

MOREIRA, Ruy. O pensamento geográfico brasileiro, vol. 3: as matrizes brasileiras. São Paulo: Contexto, 2010.

NIMER, Edmon. Climatologia do Brasil. Rio de Janeiro: IBGE, 1979.

NUNES, Luci Hidalgo. Compreensões e ações frente aos padrões espaciais e temporais de riscos e desastres. Revista Terrritorium, n.16, p. 179-189, 2009.

OLIVEIRA, Marcelo Accioly Teixeira e HERMANN, Maria Lucia de Paula. Ocupação do solo e riscos ambientais na área conurbada de Florianópolis. In: GUERRA, Antonio José Teixeira; CUNHA, Sandra Baptista (org.). Impactos ambientais urbanos no Brasil. 3a edição. Rio de Janeiro: Bertrand Brasil, 2005.

SANT'ANNA NETO, João Lima. As chuvas no Estado de São Paulo: contribuição ao estudo da variabilidade e tendência da pluviosidade na perspectiva da análise geográfica. Tese (Doutorado em Geografia). Departamento de Geografia da Faculdade de Filosofia, Letras e Ciências Humanas, Universidade de São Paulo, 1995. 
SANT'ANNA NETO, João Lima. História da Climatologia no Brasil: gênese e paradigmas do clima como fenômeno geográfico. Tese (Livre Docência). Presidente Prudente: FCT/UNESP, 2001a.

SANT'ANNA NETO, João Lima. Por uma Geografia do Clima. Revista Terra Livre. AGB: São Paulo, v. 17, p. 49-62, 2001b.

SANT'ANNA NETO, João Lima. Da climatologia geográfica à geografia do clima: gênese, paradigmas e aplicações do clima como fenômeno geográfico. Revista da ANPEGE, v. 4, p. 1-18, 2008.

SANT'ANNA NETO, João Lima. Escalas geográficas do clima: mudança, variabilidade e ritmo. In: AMORIM, Margarete C. de Costa Trindade; SANT'ANNA NETO, João Lima; MOTNEIRO, Ana (orgs.). Climatologia urbana e regional: questões teóricas e estudos de caso. 1a edição. São Paulo: Outras Expressões, 2013.

SATTERTHWAITE, David; SALEEMUL, Huq; REID, Hannah; PELLING, Mark; LANKAO, Patricia Romero. Adapting to climate change in urban areas: the possibilities and constraints in Low- and Middle-income nations. In: BICKNELL, Jane; DODMAN, David; SATTERTHWAITE, David (orgs). Adapting cities to climate change: understanding and addressing the development challenges. London: Earthscan, 2009.

SERRA, Adalberto e RATISBONNA, Leandro. O clima do Rio de Janeiro. Serviço de Meteorologia, Ministério da Agricultura, 1941

SERRA, Adalberto. O clima da Guanabara. Boletim Geográfico, v. 214, pp. 80$111,1970 a$

SERRA, Adalberto. Chuvas intensas na Guanabara. Boletim Geográfico, v. 218, p. $24-48,1970 b$

SERRA, Adalberto. Circulação no hemisfério sul. Boletim Geográfico, v. 224, p. 23-87, 1971

SILVEIRA, Renata Dias da. Relação entre os tipos de tempo, eventos de precipitação extrema e inundações no espaço urbano de São Sepé - RS. Dissertação (Mestrado). Programa de Pós-Graduação em Geografia. Santa Maria: UFSM, 2007.

TAVARES, Ricardo. Critérios de escolha de anos-padrões para análise rítmica. Geografia, Rio Claro, n.1, v.1, p.79-87, 1976.

VICENTE, Andrea Koga. Eventos extremos de precipitação na Região Metropolitana de Campinas. Dissertação (Mestrado). Programa de PósGraduação em Geografia. Campinas: Unicamp, 2004.

ZAVATTINI, João Afonso; BOIN, Marcos Norberto. Climatologia Geográfica: teoria e prática de pesquisa. Campinas: Alínea, 2013. 